\title{
Adverse Effects of Climate Change on Environment: A Review
}

\author{
Debargha Banerjee, Uddipta Ghosh", Debasish Das, Akash Debnath, \\ Ankit Kumar Singh, Shaswatika Pal, Ishita Roy and Sujoy Adhikari
}

Department of Civil Engineering, JIS College of Engineering, Kalyani, West Bengal, India

*Corresponding author: debargha189@gmail.com (ORCID ID: 0000-0002-3340-4664)

Paper No. 946

Received: $14-06-2021$

Revised: 25-08-2021

Accepted: 03-09-2021

\begin{abstract}
In present days almost $84 \%$ of world's energy is produced by burning fossil fuels and rest from others. Also almost $64.5 \%$ of electricity is generated by using fossils. As a result of burning them, a large amount of smoke is released into the atmosphere, which includes carbon dioxide and many other harmful substances, polluting the air and causing a rise in temperature. Deforestation is occurring in many places for construction purposes, but afforestation is not occurring in such a manner deforestation is occurring. It is also responsible for the enormous change in climate. So as much as we should plant, also we have to depend more on the renewable energies (Green energy) to give a balanced climate to our environment. Climate change is one of the world's most pressing environmental issues. India is confronted with a number of issues. Climate change has a number of negative consequences for agriculture, water resources, forests and biodiversity, health, coastal management, and temperature rise. The major consequence of climate change on India is a decrease in agricultural productivity. Agriculture supports the bulk of the people, either directly or indirectly. Climate change would add to the stress placed on natural and socioeconomic systems, which are already under immense strain as a result of increasing industrialization, urbanisation, and economic expansion. The impacts of climate change, as well as its different components, are discussed in this work.
\end{abstract}

\section{HIGHLIGHTS}

(0) The accumulation of trace gases such as carbon dioxide $\left(\mathrm{CO}_{2}\right)$ and methane $\left(\mathrm{CH}_{4}\right)$ in the atmosphere, mostly owing to anthropogenic activities such as fossil fuel combustion, is thought to be affecting the earth's climate system.

( India has reason to be concerned about climate change because a large portion of its population relies on climate-sensitive industries such as agriculture, forestry, and fishing for a living.

(0 The negative effects of climate change, such as decreased rainfall and rising temperatures, have exacerbated the severity of livelihood challenges in the nation.

( Although not all of the potential repercussions of climate change are completely recognised, the primary 'categories' of impacts include those on agriculture, sea level rise, and increasing frequency of severe events, all of which represent serious challenges to India.

Keywords: Fossil Fuels, Technology, Deforestation, Afforestation, Green Energy

Climate change is a vital challenge for each part of the world. Climatic Change is dedicated to the totality of the problem of climatic variation and change on impacts, various causes, \& its implementation. Humans developed many instruments by using modern technology. In this era of modernization, various techniques are used to control the effect of climate change over the whole part of the world.
Change climate may have several impacts on the modern environment in the world. Continuous and unabated emissions of millions of tonnes of carbon

How to cite this article: Banerjee, D., Ghosh, U., Das, D., Debnath, A., Singh, A.K., Pal, S., Roy, I. and Adhikari, S. 2021. Adverse Effects of Climate Change on Environment: A Review. Int. J. Ag. Env. Biotech., 14(04): 575-583.

Source of Support: None; Conflict of Interest: None 
dioxide into the atmosphere, even if originating primarily from a few countries or regions, can result in global and permanent climatic changes with potentially disastrous consequences such as rising sea levels and the submergence of numerous islands and coastal areas, as well as an increase in ambient temperatures with significant impact on crop yields (The Hindu Survey of Environment, 2009). It can generate many environmental problems like pollution of land and water, natural resources depletion, etc which may cause huge damage to the environment. The impacts of climate change vary from food scarcity to the whole life system and hence many discoveries have been made to fulfil the need of people and to maintain a luxurious life as well. As we know that fossil fuels are used to generate energy which is very much helpful in this era of modernization. Therefore this has been taken as a serious concept to identify systematically for that $\mathrm{CO}_{2}$ emission. Thus climate change plays an important role in the adverse effect of modernization.

Change in climate is certainly authentic. A disaster like a typhoon is also considered as the impact of climate change (Adedeji 2014). The emission of $\mathrm{CO}_{2}$ causes fossil fuel which causes burning or fire (Houghton 2001). Uncertain climatic circumstances such as floods, droughts, and other natural disasters become more common as the severity of the storm rises (Komariah 2018). Climate change may have cause-effect on the insects like mosquitoes because their whole cycle of life is susceptible to climatic transform from birth to adults (Roswati 2021). Change in climate occurs due to change in air pressure which causes global climate change and hence it creates flood, drought, etc. (Sujatmiko 2018). Data collected over recent days shows rapid changes in a historic concept (Stagrum 2016). Climatic change and its various temperatures may cause some change in temperature (Andrew 2009). Climate change upgrades equity consideration in which this equity is appraised as income distribution (Paul 2009). The impact of various climate changes has become more and more obvious on human nature for the implementation of changes (Jianfang 2020).

\section{Acid Rain}

Acid rain is a wide word that refers to a variety of ways in which acids are released into the atmosphere. Acid deposition is a more specific word that comprises two parts: wet and dry. Acidic rain, fog, and snow are examples of wet deposition. This acidic water has an impact on a range of plants and animals as it travels over and through the earth. Acidic gases and particles are referred to as dry deposition. Dry deposition returns around half of the acidity in the atmosphere to the ground (Wondyfraw 2014). The importance of soil quality in the preservation of structural diversity in Boreal forest ecosystems cannot be overstated. Variations in soil acidity and their relationship to biodiversity were investigated at Russia's National Natural Park "Russian North" (Kopstik et al. 2001).The changing of colour of Taj Mahal due to heavy impact of acid rain during these years due to presence of toxic industries nearby has initiated the change in colour from white to yellowish it is estimated by the Canadian government that their 14000 lakes are acidic due to this. Economic losses caused by acid rain on forestry, soil, health, agriculture, and other areas have been extensively researched (Wei et al. 2013), but economic loss estimation of building structures subjected to acid rain erosion, particularly the loss assessment of concrete, has received little attention (Tidblad et al. 2001).

\section{Rise in Sea Level}

The sea level has increased and is drastically increasing due to melting of glaciers of Arctic and Atlantic oceans. Not only sea's but the glaciars present on top of mountains have also started to melt the amount of fresh water present have also started to decline at a rapid level. Sea-level rise and rising temperatures will have an impact on the coastal ecology. Increased floods will pose the biggest threat to densely inhabited mega delta regions in particular. The Godavari, Indus, Mahanadi, and Krishna coastal deltas will shift. Thousands of people might be displaced. Sea level rise is expected to wreak havoc on aquaculture. Sectors, as well as exacerbating already low fish yield. There will also be more dangers. Coastal surges and cycles are becoming more frequent and intense (GoI 2005). Recent research of cyclone occurrences in the Bay of Bengal has revealed no changes over the previous century (Bhaskar Rao et al. 2001). Wind stress is more relevant than inverse barometric effects in coastal areas. The majority of 
early storm surge researches in India were focused on numerical modelling of specific incidents using the cyclone's track and pressure decrease as input. The storm surge model is driven by the wind fields derived using the cyclone parameters (Unnikrishnan et al. 2006). The estimations of sea-level increase along the Indian coast were based on historical tide gauge data. Mumbai, Visakhapatnam, and Kochi exhibited a sea-level increase of less than 1 $\mathrm{mm} /$ year among the stations studied; nevertheless, the investigation for Chennai revealed a rate of reduction. In order to calculate the net sea-level rise, these projections must be rectified by removing observations of vertical land motions, which are currently unavailable (Unnikrishnan et al. 2006).

\section{Food}

Global warming would represent a serious danger to global food security, but if it is kept to 1.5 degrees Celsius, the vulnerability of $76 \%$ of poor nations will be decreased compared to the same regions at 2 degrees. Climate change has a tremendous influence on agriculture productivity, making ensuring food for the world's population a difficult undertaking. To meet the population's food and nutritional needs by 2050 , the world's agricultural production must expand by $60 \%$ every year from 2005 to 2050, with a $77 \%$ increase in poor nations and a $24 \%$ increase in rich ones. Climate change is known to have a negative impact on agricultural productivity, and it is predicted that worldwide cereal production of maize and wheat will decrease by $3.8 \%$ and $5.5 \%$, respectively, as a result of climate change. Plants are subjected to abiotic stressors such as salt, drought, and heat stress as a result of climate variables (Betts et al. 2018; Alexandratos et al. 2012; Malhi et al. 2020). Agriculture in India, which is highly climate-sensitive and accounts for nearly $25 \%$ of GDP, employs $65 \%$ of the workforce, and accounts for $13.3 \%$ of total exports when combined with allied activities, contributes nearly $25 \%$ of GDP, employs $65 \%$ of the total workforce, and accounts for $13.3 \%$ of total exports (GOI 2002). Several studies suggest that, despite a significant rise in national food grain output, climate change would reduce the yield of several major crops such as rice and wheat (Achanta 1993). Flooding threats are expected to rise in the foreseeable future as glaciers melt. Long-term, there is no substitute for the water delivered by glaciers, which might result in unprecedented water shortages. As a result of climate change, floods and droughts are expected to become more common. This will result in massive crop losses and render big swaths of productive land unusable. To summarise, it will jeopardise food security. Farmers may lose between $9 \%$ and $25 \%$ of their net revenue due to a 2 to $3.5^{\circ} \mathrm{C}$ rise in temperature coupled by a $7 \%$ to $25 \%$ shift in precipitation, which might have a negative impact on GDP from the $1.8 \%$ to $3.4 \%$ (Kumar \& Parikh 1998). There will be major ramifications for the food industry. South Asia's security is in jeopardy, and India threatens to lose 125 million tonnes, or around $18 \%$ of its GDP. Its cereal production is rain fed (Fisher et al. 2001). By 2010, India's overall food grain demand is expected to reach more than 250 million tonnes. By 2010, the gross arable area is predicted to rise from 191 to $215 \mathrm{mha}$, necessitating a $150 \%$ increase in cultivation intensity (Sinha et al. 1998). Because land is a finite resource for agriculture, the only way to meet India's growing food demand is to increase yield per unit of land, water, energy, and time, as achieved by precision farming. Even with farm-level adjustments, the consequences of climate change on Indian agriculture will be severe, according to Kavi Kumar and Parikh (2001). They calculated that a temperature increase of $+2^{\circ} \mathrm{C}$ with an accompanying precipitation change of $+7 \%$ would result in a $9 \%$ drop in farm level total net-revenue, whereas a temperature increase of $+3.5^{\circ} \mathrm{C}$ with an accompanying precipitation change of $+15 \%$ would result in a nearly $25 \%$ drop in farm level total net-revenue. Mall et al. (2006) present a thorough evaluation of climate change impact research on Indian agriculture, focusing on physical effects. Under climate change, there is a considerable decline in yields of essential cereal crops like rice and wheat, according to existing information.

\section{Temperature}

According to the Intergovernmental Panel on Climate Change, global mean temperature might rise by 1.4 to $5.8^{\circ} \mathrm{C}$ by 2100 . The global hydrological system, environment, sea level, crop output, and associated processes are all projected to be severely impacted by this unprecedented rise. The impact will be more severe in tropical areas, which are mostly populated by poor countries like India 
(Jayant et al. 2006). It has been seen that summer is getting warmer and winter is getting much colder. Across the continents of United States in the 1960s the daily recorded low temperature was more than record highs, but in the 2000s it changed to twice as many record highs as record low. To summarize, it will jeopardize food security. Farmers may lose $9 \%$ to $25 \%$ of their net revenue due to a 2 to $3.5^{\circ} \mathrm{C}$ rise in temperature coupled by a $7 \%$ to $25 \%$ change in precipitation, which may negatively influence GDP by $1.8 \%$ to $3.4 \%$ (Kumar and Parikh 2001). Food security in the south would be jeopardized, with India losing 125 million tonnes of rain fed cereal output, or around $18 \%$ of its total (Fisher et al. 2001). According to Kumar and Parikh (2001), a temperature change of $+2^{\circ} \mathrm{C}$ with an accompanying precipitation change of $+7 \%$ would result in a $9 \%$ drop in farm level total net-revenue, whereas a temperature increase of $+3.5^{\circ} \mathrm{C}$ with an accompanying precipitation change of $+15 \%$ would result in a nearly $25 \%$ drop in farm level total netrevenue.

\section{Cause of Climate Change}

With growing population and heavy dependence on machinery we have developed tendency to ease our life at the cost of environment.

\section{Deforestation}

Trees provide a cool weather and a beautiful environment. They are the reason for rain, maintaining oxygen and carbon dioxide level in atmosphere, providing clean and cool weather. One of the main reasons for climate change would be this. Deforestation is one of the key causes of climate change, according to overwhelming evidence and consensus. Industrial sources, notably the burning of fossil fuels, are projected to account for 75 to $80 \%$ of world emissions. Deforestation emissions, primarily in the tropics, account for the remaining 20 to $25 \%$. To safeguard the world's biodiversity and people from catastrophic climate change, both fossil fuel use and deforestation must be handled immediately and efficiently. Currently, there is a fresh chance to address the issue of deforestation within the context of the climate change regime (IPCC 1996). Rising concentrations of so-called greenhouse gases (GHGs) are now generally recognised as causing changes in Earth's climatic patterns, resulting in catastrophic weather events such as hurricanes, heat waves, droughts, and floods, and endangering plant and animal life. Forests are important for preventing climate change and managing climatic trends because trees - trunks, branches, and roots - and even soil absorb and store $\mathrm{CO}_{2^{\prime}}$ creating a natural reservoir for this greenhouse gas (Shue 1999).

\section{Fossil Fuels}

The burning of fossil fuels (coal, diesel fuel, gasoline, oil, and natural gas) for power production, heating, transportation, and industry produces the bulk of global air pollution. In 2011, fossil fuels accounted for $82 \%$ of the world's total primary energy supply. Oil, natural gas, and coal constitute for $81 \%$ of current fuel usage in the United States (World Energy Resources 2013). Energy-related fossil-fuel combustion in high- and middle-income countries, as well as biomass burning in low-income countries, is responsible for the majority of global air pollution, accounting for $85 \%$ of airborne respirable particulate pollution and nearly all sulphur dioxide and nitrogen oxide emissions (IEA 2016). The burning of fossil fuels emits high amount of carbon dioxide resulting in its accumulation in troposphere. These gas increases the internal temperature of earth along with causing breathing problems. WHO's lowand middle-income nations. In 2012, the South-East Asia and Western Pacific regions bore the brunt of the air pollution load, with 2.6 million fatalities from outdoor air pollution and 3.3 million deaths from interior air pollution (WHO 2017). In contrast to pollution-related deaths, which disproportionately affect adults over 60, disability-adjusted life years (DALYs) resulting from pollution-related disease are concentrated disproportionately among infants and young children, reflecting their vulnerability and the many years of life lost with each child's death (WHO 2010).

\section{Greenhouse Gasses}

Greenhouse gasses are protecting out earth from UV rays. However, chlorofluorocarbons, as well as other pollutants, are emitted. These pollutants are depleting the ozone layer .the biggest depletion of ozone layer spotted till date is in Antarctica resulting in increase in melting of icebergs present out .Temperature, precipitation, air humidity and soil, the status of the snow and ice cover, and a 
variety of other factors all contribute to the climate. Due to a variety of natural reasons, the climate is continually changing. Human activity has become a key new component that has been impacting the Earth's climate more and more in the last 200 years. The greenhouse effect (Moumen et al. 2019; Chehabeddine \& Tvaronaviien 2020) defines its effects resulting in increase in internal temperature of earth surface. Humans also contribute a lot for depletion of greenhouse gasses. Due to the amplification of the greenhouse effect, the world average temperature is progressively rising, and atmospheric $\mathrm{CO}_{2}$ concentration has surpassed 400 ppm. The energy balance approach was used to simulate trends in Greenhouse Gas Emission Forecast in several industries till 2030. We discovered that reducing anthropogenic $\mathrm{CO}_{2}$ emissions from humans (cars and residences) would mitigate the effects of the above trends using sensitivity analysis. Emissions are largely linked to industry, which may be lowered if local governments desire to meet the Paris Agreement's target (Mikhaylov et al. 2020).

\section{Pollutants Released}

Although the industrial revolution was a big success in terms of technology and the supply of a wide range of services, it also resulted in the release of massive amounts of pollutants into the air that are hazardous to human health. Global environmental contamination is seen as a multifaceted worldwide public health concern. This big issue is linked to social, economic, and legislative problems, as well as lifestyle behaviors. In our day, urbanization and industrialization are reaching unprecedented and unsettling levels over the world. Anthropogenic air pollution is one of the world's most serious public health threats, causing around 9 million fatalities each year (WHO 2019).

\section{Mitigation - Reducing the Adverse Effect of climate change}

\section{Less use of fossil fuels and Use renewable energies}

As we all know fossil fuels plays a vital role for generating energy and electricity as well. But it emits a smoke which contains carbon dioxide and many more toxic gases as burning of fossil fuels releases toxic gases so it harms to the environment and changes the climate. As much as the air is polluting, the temperature also increases in a vigorous manner and responsible for global warming. So the use of fossil fuels must be minimal as far as possible. The timing of mitigation activities is essential, especially if geo engineering approaches that have yet to be demonstrated are to be avoided. Clearly, switching from fossil to renewable, clean energy sources has the potential to reduce aerosol pollution-related morbidity and death. Because the particles have a net climate cooling impact, eliminating them would reduce the likelihood of fulfilling the Paris Agreement's targets, but the public health benefit is still a compelling reason to reduce emissions (Shindell et al. 2018). Faced with the problems of dwindling fossil fuel supplies and the environmental disaster resulting from the usage of fossil fuels, finding sustainable and clean fuels for future applications is becoming increasingly necessary. In a larger sense, the term "alternative fuels" may refer to more than simply replacing fossil fuels; it may also refer to the development endeavour of preserving current biodiversity while employing cleaner energy. If the planet is to remain safer for future generations, the adoption of sustainable energy fuel will undoubtedly transcend the current generation. Biomass fuels, municipal solid waste, hydrogen, alcohols, nitrogen hydrides, and nitro-hyrocarbons are all viable fossil fuel energy alternatives. These fuels share one common quality in previous works: they are readily available and easy to get with little or no effort. Furthermore, they must possess qualities that allow them to store energy in order to qualify as energy sources. This property qualifies them to contain sufficient amounts of substance for energy development (Hutter et al. 2015). One of the main benefits of biomass energy is that it can be used in other aspects of life in a similar way to fossil fuels, and it can be supported by current technology and is acceptable to other electric utility customers. The high moisture content and increased ash content of biomass energy sources are two of its major drawbacks. Because of its availability and the government's incapacity to adequately manage this portion of waste volume, municipal solid waste (MSW) is receiving interest as an energy source. MSW, or municipal trash, is made up of solid waste from daily goods such as furniture, clothing, bottles, food scraps, newspapers, and appliances, among 
other things. One of the most common uses of MSW fuel is to create electricity, as demonstrated in the United States, where a dedicated MSW power plant was built to convert garbage to energy. The current challenge in converting MSW to energy fuels is due to the fact that MSW-derived fuels may require beneficiation, which may require the removal of some contaminants or sewage sludge, both of which are still expensive to adapt as a power plant in poor nations. India's national government is increasingly concentrating on renewable energy generation. These were incorporated into their five-year plan. Renewable energy is taught at India's technical institutes for one or two semesters. Some technical institutes in India have begun to offer undergraduate and postgraduate renewable energy programmes. Student projects that utilise sustainable energy sources are also being funded by the government (Khare et al. 2015).

\section{Afforestation}

Sustainable afforestation entails seeing the forest as a whole rather than as a source of a single economic commodity or service (GEF 2010). The rationales for afforestation have mostly been limited to environmental or social advantages, social economy stimulation, and multiplier effects (Oyen and Nygaard 2000). Carbon sink, soil and water protection, wind break, wildlife habitat, reduced strain on natural forests, and promotion of outdoor activities and public health are some of the environmental and social advantages that may be derived by continued tree planting.

As use of fossil fuels harms the environment so the use of it must be the minimum as much as possible. But we know maximum \%age of energy is produced by burning fossil fuels, so we cannot stop energy production as it is a daily basis need. Carbon sequestration: Under the Kyoto Protocol, afforestation (or tree planting) is recognised as a qualifying activity for reducing greenhouse gas emissions (GHG). Afforestation predominantly balances atmospheric $\mathrm{CO}_{2}$ as a carbon sequestration activity (IPCC 2000). Photosynthesis fixes carbon, which is then stored in the biomass of trees above and below ground. The forestry sector's mitigation strategies include extended carbon retention in harvested wood products, product substitution, and biomass production for bio-energy. This carbon is taken out of the atmosphere and made accessible to civilization in the form of lumber, fibre, and electricity. Forest biomass may contribute 12-74 EJ/yr to energy consumption, with a mitigation potential of 0.4-4.4 $\mathrm{GtCO}_{2} / \mathrm{yr}$ depending on whether biomass replaces coal or gas in power plants (Nabuurs et al. 2007). Furthermore, it is absorbed into the soil by the roots and the breakdown of forest detritus or litter (Freedman and Keith 1998). Afforestation can also help with energy supply by making fuelwood more affordable and available. Wood, after petroleum and natural gas, is the third most valuable commodity for energy supply on a worldwide scale (WRI 1990). For domestic energy, more than two-thirds of people in underdeveloped nations rely only on wood (Oyedele 2008). In 1999, it was projected that 1.46 million tonnes of fuel wood were generated throughout the world, accounting for $5 \%$ of total energy use (FAO 2001). The majority of the wood gathered is burnt in the form of wood or charcoal, briquettes, or pellets to cook meals, heat houses, and fuel rural enterprises (Thomas 2010).

\section{Adopt sustainable transportation}

On our daily basis transportation a huge number of vehicles are required. Maximum vehicles use fossil fuels for generating energy, so that these releases smokes which make the air polluted. Global worries about climate change, environmental implications, and limited financial resources have recently highlighted the need for a new approach to transportation solution selection. As a result, there is an increasing demand in the transportation infrastructure system to promote environmental sustainability. A sustainable transportation system must be safe, healthy, accessible, and renewable, as well as equitable in terms of harmful gas emissions and non-renewable resource consumption. Hsu and Wang (2015) argue in favour of promoting sustainable transportation that is both accessible and mobile. The writers address the notion of using various modes of transportation to reduce environmental concerns. Using electric buses in conjunction with rapid transit vehicles is a more energy-efficient option than using traditional private autos. However, because of the quickness of travel, people still choose to utilise private automobiles. Buwana et al. (2016) conducted a study in Kasongan City, the Katingan district's 
capital. The increased use of highways rather than the Katingan River, which was once the region's primary mode of transportation, is explained by the growth of motorbikes, which reached $91.9 \%$ in 2013. The transportation sector accounted for roughly $53.33 \%$ of total $\mathrm{CO}_{2}$ emissions each year. The analytic hierarchy technique was used to explore essential factors for selecting the most appropriate solution for developing sustainable transportation networks (AHP). According to Khan et al. (2017), a company's sustainable supply chain plays an essential role in both environmental and financial issues. In recent decades, businesses have shown a growing proclivity to incorporate environmentally friendly methods into their operations. There is no question that there are certain driving elements in regard to sustainable development, such as cost savings through recycling, repurposing, and remanufacturing. Customers' demand and rigorous government environmental legislation, on the other hand, force businesses to embrace environmentally friendly methods. When examining the benefits of using sustainable transportation techniques, it was discovered that the study analysis reached a consensus conclusion concerning the methodology taken to reduce polluting gases such as $\mathrm{CO}_{2}$ in the atmosphere. Beyond that, the improvement of urban transportation conditions and the benefits created in the performance of firms that value the adoption of sustainable practices may be seen. The high cost of usage of sustainable transportation means is underlined, as is the population culture in regard to non-use and recognition of the relevance of those ways, a reality that has improved significantly over the years (Martins et al. 2019).

\section{Waste management and recycling}

In our daily activity we humans produce many wastes such as household wastes, medical wastes etc. Waste is always produced by human activities. When the human population was tiny and nomadic, this was not a huge concern, but it became a severe one when cities grew and vast conurbations grew. Poor waste management resulted in contamination of water, land, and the atmosphere, as well as an increase in pollution. It has a significant influence on public health. The qualities of waste material have changed in response to changes in the environment. The number of novel chemical chemicals found in various waste streams has grown as a result of changing lifestyles dramatically (Singh et al. 2018). Garbage incineration (with energy recovery) can reduce the volume of waste disposed of by up to $90 \%$. Only waste streams with substantial volumes of packaging materials, paper, cardboard, plastics, and horticulture waste show this high volume reduction. In general, due to costs and pollutants, incineration without energy recovery is not a recommended alternative. Incineration of waste is costly and problematic in terms of air pollution and ash disposal. Incineration necessitates the containerization of trash left outside for collection in order for it to stay dry, and much of the waste stream is non-combustible. Unfortunately, one tonne of municipal solid waste (MSW) incineration produces roughly one tonne of carbon dioxide; but, if the same quantity of MSW was land filled, 62 cubic metres of methane would be created. This has the potential to cause twice as much global warming as a tonne of carbon dioxide. The incineration process may generate both heat and electricity: 600 tonnes of garbage per day can generate $17 \mathrm{MW}$ of electricity and 1200MWh of district heating per day (World Bank 1999). Electronic items reaching the end of their "useful life" are referred to as "e-waste." E-wastes are harmful because certain components of electronic items contain toxic elements, depending on their state and density. These materials' toxic composition endangers human health and the environment. If incorrectly disposed of, computers, televisions, VCRs, stereos, copiers, fax machines, electric lights, mobile phones, audio equipment, and batteries can leach lead and other contaminants into soil and groundwater. Many of these items may be reused, reconditioned, or recycled without harming the environment (Rao 2014).

\section{CONCLUSION}

Climate change is projected to have a wide range of effects on human well-being, including capital, ecosystem, illness, and migration. Regardless of the severity of the issue, the existing condition of economics makes it difficult to calculate the worth. At the least, real development entails a shift from an agricultural to a nonagricultural economy, diminishing reliance on agriculture. Because the majority of the labour force-roughly $70 \%$ - depends on the sector for their subsistence 
and work, when it becomes more productive and assures food self-sufficiency, it will free up labour and capital for the manufacturing and service sectors. In the context of the present discussion on climate change, it is vital to demonstrate that, far from being inert, India is taking significant policy, programme, and project activities. Technology transfer can hasten modernisation, while greater cash can hasten government efforts to conserve energy. However, initiatives aimed at reducing poverty must be prioritised.

\section{REFERENCES}

Achanta, A.N. 1993. An assessment of the potential impact of global warming on Indian rice production, In Achanta A N (ed). The Climate Change Agenda: An Indian Perspective, TERI, New Delhi.

Alexandratos, N. and Bruinsma, J. 2012. World Agriculture: Towards 2030/2050; ESA Working Paper No. 12-03; FAO: Rome, Italy.

Andrew Ross and Damon Matthews, H. 2009.Climate Engineering and the risk of rapid climate change. Environ. Res. Lett., 4: 045103.

Betts, R.A., Alfieri, L., Bradshaw, C., Caeser, J., Feyen, L., Friedlingstein, P., Gohar, L., Koutroulis, A., Lewis, K., Morfopoulos, C., et al. Changes in climate extremes, fresh water availability and vulnerability to food insecurity projected at $1.5^{\circ} \mathrm{C}$ and $2^{\circ} \mathrm{C}$ global warming with a higherresolution global climate model. Phil. Trans. R. Soc. A., 376-452.

Buwana, E., Hasibuan, H.S. and Abdini, C. 2016. Alternatives selection for sustainable transportation system in Kasongan City. In: International conference, intelligent planning towards smart cities, Surabaya.

Chehabeddine, M. and Tvaronavičienè, M. 2020. Securing regional development. Insights into Regional Dev., 2(1): 430-442.

Decision Makers' Guide to Municipal Solid Waste Incineration The World Bank Washington, D.C pg no 01.

Development and India: Global and National Concerns", Current Sc., 90(3): 314-325.

FAO, 2001. The role of wood energy in developing countries. FAO-Forestry Department Working Paper. FOPW/00/1. Rome.

Fisher Gunther, Mahendra Shah, Harrij Van Velthuizen and Freddy Nechtergaele, O. 2001. "Global Agro-Ecological Assessment for Agriculture in the 21st Century", Int. Institute of Appl. Systems Analysis, pp. 27-31, Austria.

Freedman, B. and Keith, T. 1998. Planting trees for carbon credits: a discussion of context, issues, feasibility, and environmental benefits. Environ. Rev., 4: 100-111.

Global Environment Facility, GEF, 2010. Global Action on sustainable land management.
GoI (Various Issues), Economic Survey, Government of India.

Houghton, J.T., Ding, Y., Griggs, D.J., Noguer, M., van der Linden, P.J., Dai, X., Maskell, K., Johnson, C.A. 2001: The Scientific Basis. Contribution of Working Group I to the Third Assessment Report of the Intergovernmental Panel on Climate Change. Intergovernmental Panel on Climate Change. Archived from the original on 2007-12-31.

Hsu, C-I. and Wang, H.M. 2015. Strategies for green transportation while preserving mobility and accessibility: a case study of Taipei City. J. Urban Plann. Dev., 142: 04015008.

Hutter, H.P., Kundi, M., Moshammer, H., Shelton, J., Krüger, B. and Schicker, I. Replacing fossil diesel by biodiesel fuel: Expected impact on health, Archives of Env. E Occupational Heal., 70: 4-9.

Intergovernmental Panel on Climate Change (IPCC), 2000. Land Use, Land Use Change, and Forestry, Summary for Policymakers. Cambridge University Press, Cambridge, UK. pp. 377.

International Energy Agency (IEA). Weo-2016 Special Report Energy and Air Pollution; International Energy Agency: Paris, France, 2016, pp. 266.

IPCC, 1996. “Climate Change 1995. Impacts, Adaptation, and Mitigation of Climate Change: Scientific-Technical Analyses", Watson, R.T., Zinyowera, M.C., and Moss, R.H., (eds), Contribution of Working Group II to the Second Assessment of the Intergovernmental Panel on Climate Change, Cambridge: Cambridge University Press.

Jianfang Zong, Liang Sun and Wei Bao. 2020. Thoughts on addressing climate change. Earth Environ. Sci., 510-042004

Khan, S.A.R., Qianli, D. and Zhang, Y. 2017. The impact of green supply chain on enterprise performance: in the perspective of China. J. Adv. Manuf. Syst., 16: 263.

Khare, S., Bajpai, S. and Bharati, P. 2015. Production engineering education in India. Mgt. and Prod. Engg. Rev., 6(1): 21-25.

Komariah, 2018. International conference on climate change. Earth Environ. Sci., 200-011001.

Kopstik, G.N., Kopstik, S.V. and Aamlid, D. Pine needle chemistry near a large point $\mathrm{SO}_{2}$ sources in northern Fennoscandia. Water Air Soil Pollut., 130: 929-934.

Kumar, K.S. and Parikh, J. 2001. "Socio-economic Impacts of Climate Change on Indian Agriculture", Int. Rev. of Env. Strategies, 2(2): 277-293.

Malhi, G.S., Kaur, M., Kaushik, P., Alyemeni, M.N., Alsahli, A. and Ahmad, P. 2020. Arbuscular mycorrhiza in combating abiotic stresses in vegetables: An eco-friendly approach. Saudi J. Biol. Sci.

Mall, R.K., Singh, R. and Gupta, A. et al. 2006. "Impact of Climate Change on Indian Agriculture: A Review", Climate Change, 78: 445-478.

Martins, V., Anholon, R. and Quelhas, O. 2019. Sustainability Transportation Methods. In Encyclopedia of Sustainability in Hugher Education; Filho, W.L., Ed.; Springer Nature: Cham, Switzerland, 2019; pp. 1-7. 
Mikhaylov, A., Moiseev, N., Aleshin, K. and Burkhardt, T. 2020. Global climate change and greenhouse effect. Entrepreneurship and Sustainability Issues, 7(4): 2897-2913.

Moumen, Z., El Idrissi, N.E.A., Tvaronavičienė, M. and Lahrach, A. 2019. Water security and sustainable development. Insights into Reg. Dev., 1(4): 301-317.

Nabuurs, G.J., O. Masera, K. Andrasko, P. Benitez-Ponce, R. Boer, M. Dutschke, E. Elsiddig, J. Ford-Robertson, P. Frumhoff, T. Karjalainen, O. Krankina, W.A. Kurz, M. Matsumoto, W. Oyhantcabal, N.H. Ravindranath, M.J. Sanz Sanchez, Zhang, X. 2007. Forestry. In Climate Change 2007: Mitigation. Contribution of Working Group III to the Fourth Assessment Report of the Intergovernmental Panel on Climate Change [B. Metz, O.R. Davidson, P.R. Bosch, R. Dave, L.A. Meyer (eds)], Cambridge University Press, Cambridge, United Kingdom and New York, NY, USA. 44pp. No. 2, pp. 277-293.

Oloyede, I.O. 2008. Afforestation and Reforestation: The Unilorin Experiment. A presentation at the high level technical workshop on afforestation and climate change in Africa, pp. 23.

Olufemi Adedeji, Reuben Okocha, Olufemi Olataye.2014. Global Climate Change. J. Geosc. Env. Prot., 02(02): 114-122.

Oyen, B.H. and Nygaard, P.H. 2000. Effects of afforestation on wood production and forest yield. Afforestation in Nordic countries, pp. 30-35.

Paul Baer. 2009. Equity in climate - economy scenarios: the importance of sub national income distribution. Curr. Sc., 90(3): 362-368.

Rao, L. Nageswara. 2014. Environmental Impact of Uncontrolled Disposal of E-Wastes. Int. J. of Chem Tech Res., 6(2): 1343-1353.

Roswati, Santi, Ahmad Syafii, Eke Mahendra and Ramadhan Tosepu, 2021. A Systematic literature (Impact of climate change on Filariasis). Earth Environ. Sci., 755-0102083.

Shindell, D., Faluvegi, G., Seltzer, K. and Shindell, C. 2018. Quantified, localized health benefits of accelerated carbon dioxide emissions reductions. Nat. Clim. Chang., 8: 291-295.

Shue, H. 1999: Global environment and international inequality. Int. Aff., 75: 531-545.

Singh, J., Saxena, R., Bharti, V. and Singh, A. 2018. The importance waste management to environmental sanitation: A Review. Adv. Biores. 9(2): 202 -2 07.
Sinha, S.K., Rai, M. and Singh, G.B. 1998. "Decline in Productivity in Punjab and Haryana: A Myth or Reality?", p. 89, Indian Council of Agricultural Research (ICAR) Publication, New Delhi, India.

Stagrum, A.E., Kvande, T., Engebo, A., Andenaes, E. and Lohne, J. 2019. Climate implication and adaption measures for energy use in buildings - a scoping review. Earth Environ. Sci., 297-012035.

Sujatmiko, T. and Ihsaniyati, H. 2018. Implication of climate change on coffee farmers welfare in indonesia. Earth Environ. Sci., 200-012054.

The Hindu Survey of Environment, 2009.

Thomas, J. 2010. Sustainable tree planting: Benefits, challenges and the way forward. A Seminar presentation paper submitted to the Department of Forestry and Wildlife, University of Maiduguri, Maiduguri. Borno State, pp. 12.

Tidblad, J., Kucera, V. and Mikhailov, A.A. 2001. Mapping of acid deposition effects and calculation of corrosion costs on zinc in China. Water Air Soil Poll, 130: 1469-74.

Unnikrishanan, A.S., Rupa Kumar, K., Sharon E Fernandes, Michael, G.S. and Patwardhan, S.K. 2006. "Sea Level Changes Along the Indian Coast: Observations.

Wei, J., Guo, X. and Marinova, D. 2013. Industrial $\mathrm{SO}_{2}$ pollution and agricultural losses in China: evidence from heavy air polluters. J. Clean Prod., 64: 404-13.

WHO Air Pollution. WHO. 2019. Available online at: http:// www.who.int/airpollution/en/ (accessed October 5, 2019).

Willetts, E., Guadagno, L. and Ikkala, N. 2010.Addressing Climate Change, Issues and Solutions from around the World, pp. 40).

Wondyfraw, M. 2014. Mechanisms and Effects of Acid Rain on Environment. J. Earth Sci. Clim. Change, 5: 204.

World Energy Council. World Energy Resources, 2013. Survey: Summary; World Energy Council: London, UK, pp. 29.

World Health Organization. 201. 7 Million Premature Deaths Annually Linked to Air Pollution.

World Health Organization. 2010. Global Status Report on No communicable Diseases; World Health Organizations: Geneva, Switzerland, pp. 176.

World Resources Institute, WRI. 1990. World Resources 199091: A guide to the Global environment. Oxford University Press. New York. 
